\title{
Urolithiasis and intracorporeal lithotripsy in 37 Military Hospital, Accra, Ghana
}

\author{
Ben Adusei, Sunny Mante, Paul Yegbe, Joshua Amegbor \\ Ghana Med J 2019; 53(4): 304-307 doi: http://dx.doi.org/10.4314/gmj.v53i4.9
}

\author{
${ }^{1}$ Department of Urology, 37 Military Hospital, Accra
}

Corresponding author: Dr. Ben Adusei

E-mail: baks02016@yahoo.com

Conflict of interest: None declared

\section{SUMMARY}

Objective: The purpose of this study was to determine the indications and complications of intracorporeal lithotripsy in our institution.

Methods: Retrospective study carried out at the urology unit of the 37 Military Hospital between 2012-2015. 42 patients had intracorporeal lithotripsy out of 359 patients who had surgery within the period. Records of all patients who had intracorporeal lithotripsy between December 2012 to December 2015 were collected and analysed. An endourology log sheet was used to record data of patient's name, age, sex, indication for operation, location of stone, intraoperative complications, type of instruments/materials used, stone analysis and follow-up dates. All patients between the ages of six months to seventy years presenting with urinary stones diseases within the period were included, whilst patients with urinary stone disease who were managed with open surgery were excluded.

Ethical clearance was obtained from the 37 Military Hospital institutional review board

Results: Lithotripsy constituted 42/359(11.7\%) of the methods used in the surgical cases done within the period.

The commonest age of presentation was between 31-40 years (26.2\%), with a male to female ratio of 2:1. The commonest indications for lithotripsy were pain $(92.8 \%)$ and hydronephrosis $(61.9 \%)$. Ureteric stones are more common $(50 \%)$, followed by renal stones $(45 \%)$ with the commonest site being the proximal ureter. The commonest procedure was ureteroscopy. Ureteral mucosal injury (5/43) (11.62\%), was the commonest intraoperative complication. Postoperative complications were reno-cutaneous fistula (1/43) (2.32\%), severe bleeding (1/43) (2.32\%) haematuria (4/43) $(9.30 \%)$.

Conclusion: Pain was the commonest indication for intra-corporeal lithotripsy $(92.8 \%)$ and also the commonest postoperative complication $(9.30 \%)$.

Keywords: lithotripsy, intracorporeal, percutaneous nephrolithotomy, ureteroscopy, urolithiasis Funding: None declared

\section{INTRODUCTION}

Urinary stone disease is a serious health problem for a proportion of patients, in terms of incidence, recurrence rate and treatment cost in Ghana. Open surgery had been the main treatment modality in our environment despite the use of minimally invasive surgery in the industrialized countries for decades. Urolithiasis is a complex disease, thus an understanding of the epidemiology, and the interactions among different factors, may help lead to approaches that reduce the risk of stone formation. ${ }^{1}$

In adults, urinary calculus is the third most common urologic disease after urinary tract infection and prostatic disease, with a lifetime prevalence of $10-15 \% .{ }^{2}$ In the industrial countries the prevalence is $4-10 \%$. In Germany the prevalence increased from 4.0 to $4.7 \%$ during the period 1980-2000. The incidence at present is $1.4 \%{ }^{3}$
The prevalence has risen over the past 20-30years. It is becoming apparent that urolithiasis is part of a larger "metabolic picture" made up of type 2 diabetes, dyslipidaemia, hypertension, and obesity. ${ }^{4}$

In the newborn and infants it is the result of different metabolic, genetic, nutritional, and anatomic disorders. Urolithiasis in the newborn and infants represents $20 \%$ of the sum total of pediatric lithiases in the literature. ${ }^{5}$ Paediatric stone disease is endemic in Turkey, Pakistan and in some South Asian, African and South American countries. Nephrolithiasis affects boys and girls equally and is identified 1 in 1,000 to 1 in 7,600 hospital admissions in United States . It is estimated that almost $50 \%$ of stone formers will have a recurrence within 10 years. ${ }^{6}$ 


\section{Special Article}

The diagnosis of urolithiasis is mostly dependent on clinical presentation, physical examination and confirmed by radiography. The most common presentations include pain, recurrent urinary tract infections and haematuria. Non-contrast helical CT-scan has become the gold standard for the identification of calculi.

Non-contrast helical CT scan provides several advantages over the kidney, ureters and bladder (KUB) radiograph such as detection of radiolucent calculi, sensitivity for small stones, identification of other causes of flank pain as well as avoidance of any preparation prior to the procedure. ${ }^{7}$ The management of upper tract stone disease is slowly shifting from extracorporeal shockwave lithotripsy to retrograde ureteroscopic and percutaneous approaches. ${ }^{8}$

Open surgery is now obsolete but can be an option due to lack of endourologic equipment, lack of surgical expertise in modern technology, or stones in anomalous urological sites. Complications of stone disease can either be from the disease process itself or from the treatment. Complications resulting from surgical treatment will depend on type of approach, existing pre-operative complications; for example, presence of urinary tract infections, impacted stones, presence or absence of obstruction with or without renal impairment. Surgeons experience may also impact on the complication rate depending on the case load. These may also determine the nature of the post-operative complications. Complications from surgery may range from mucosal injury, bleeding, ureteral perforations, renal pelvic avulsion and pain.

Recent introduction of minimally invasive surgeries to our treatment armamentarium has led to the treatment of most of our stones endoscopically with the relegation of open surgery. The aim of the study was to determine the indications and complications of intracorporeal lithotripsy at the 37 Military Hospital. The specific objectives were (a) to determine the main indications for intracorporeal lithotripsy and (b) determine the type of complications of intracorporeal lithotripsy at the 37 Military Hospital.

\section{METHODS}

This was a retrospective study carried out at the Urology Unit of the 37 Military Hospital between December 2012 and December 2015. Records of all patients presenting to the 37 Military Hospital with urinary stone disease between the periods of December 2012 to December 2015 were collected. Information of all patients who had intracorporeal lithotripsy were also collected and analysed. An endo-urology log sheet was used during the procedure to record patient's name, age, sex, indication for operation, location of stone, intraoperative complications, type of instruments/materials used, stone analysis and followup dates.

\section{Inclusion/exclusion criteria}

All patients between the ages of six months to seventy years presenting with stones diseases within the period were included. Patients presenting with recurrent pains, recurrent urinary tract infection (UTI), bilateral obstruction, and those with renal impairment all due to stones were also included.

Exclusion criteria: Patients with stone disease who were managed with open surgery or conservatively.

Patients were followed up on out-patient basis post- operatively from December 2012 to December 2015. Patients with urinary tract infection (UTI) were treated for at least one week with antibiotic before the procedure. Those with deranged renal function from obstruction had a nephrostomy tube or a double pigtail ureteric stent inserted to correct it before intervention. Equipment and devices used include; semi-rigid ureteroscope, flexible ureteroscope, holmium laser, pneumatic lithotripter, stone baskets, stone graspers, nephroscope, guide wires, ureteric access catheter, a C-arm fluoroscope and iopamirol contrast material.

Post operatively, patients were monitored for 48-72 hours to ensure they were pain free and had no heamaturia before they were discharged. Almost all patients had a double pig-tail ureteric stent inserted post operatively. Stents were removed in 4-6 weeks. Patients were followed on out-patient basis with a repeat CT-scan or an abdominopelvic ultrasonography to indicate stone clearance.

Ethical approval was obtained from the 37 Military Hospital institutional review board.

\section{RESULTS}

A total of $42(11.7 \%)$ patients had intracorporeal lithotripsy out of a total number of 359 patients who had surgery in the unit within the period. The commonest age of presentation was between the ages of 31-40 years (26.2\%) (Table 1), with men (29) more likely to develop stones than women (13) in a ratio of about 2:1.

The commonest indication for lithotripsy was pain $(92.8 \%)$ and hydronephrosis $(61.9 \%)$ (Table 2). Ureteric stones were more common $(50 \%)$, followed by renal stones $(45 \%)$ (Table 3$)$. The commonest sites for ureteric stones was at the pelvi-ureteric junction (52\%). The commonest procedure performed was ureteroscopy constituting $72.10 \%$. The remainder were percutaneous nephrolitotomy, $9(20.93 \%)$ and cystolitholapxy $3(6.97 \%)$. 
Table 1 Age distribution of participants

\begin{tabular}{|l|l|}
\hline Ages & Frequency (\%) \\
\hline Less than 1 & $1(2.4)$ \\
\hline $\mathbf{1 - 1 0}$ & $1(2.4)$ \\
\hline $\mathbf{1 1 - 2 0}$ & $1(2.4)$ \\
\hline $\mathbf{2 1 - 3 0}$ & $6(14.2)$ \\
\hline $\mathbf{3 1 - 4 0}$ & $11(26.2)$ \\
\hline $\mathbf{4 1 - 5 0}$ & $8(19.0)$ \\
\hline $\mathbf{5 1 - 6 0}$ & $7(16.7)$ \\
\hline $\mathbf{6 1 - 7 0}$ & $7(16.7)$ \\
\hline TOTAL & $42(100)$ \\
\hline
\end{tabular}

The Stone sizes ranged from $6 \mathrm{~mm}$ to $6.68 \mathrm{~cm}$ for ureteric stones and $2.2 \mathrm{~cm}$ to staghorn for renal stones. Bladder stones were not measured as most of them were diagnosed by plain radiographs.

Table 2 Indications for lithotripsy

\begin{tabular}{|l|l|}
\hline Indications & Frequency $\mathbf{( \% )}$ \\
\hline Pain & $39(92.8)$ \\
\hline Uti/urosepsis & $9(21.4)$ \\
\hline Hydronehrosis & $26(62.0)$ \\
\hline Heamaturia & $1(2.4)$ \\
\hline Elevated creatinine & $5(12.0)$ \\
\hline Anuria & $1(2.4)$ \\
\hline
\end{tabular}

Table 3 Location of stones

\begin{tabular}{|c|c|}
\hline Location & Number (\%) \\
\hline Kidney & $19(45.2)$ \\
\hline 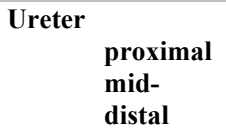 & $\begin{array}{l}21(50.0) \\
11(52.4) \\
1(4.8) \\
9(42.8)\end{array}$ \\
\hline Bladder & $3(7.1)$ \\
\hline
\end{tabular}

The commonest intraoperative complication was ureteral mucosal injury $(5 / 43)(11.62 \%)$ whilst the commonest postoperative complication was pain (6/43) $(13.95 \%)$. The other complications are as shown in Table 4.

Table 4 Intraoperative and post-operative complication among the participants

\begin{tabular}{|l|l|l|}
\hline Complications & Number & Intervention \\
\hline INTRAOPERATIVE & & \\
\hline PCNL & 2 & retrieved \\
\hline Guide wire breakage & 1 & retrieved \\
\hline "Dropped stone" & & \\
\hline URS & 5 & stented \\
\hline Vesico-ureteric injuries & 2 & stented \\
\hline Renal perforations & 1 & stented \\
\hline POST-OPERATIVE & & \\
\hline PCNL & & Transfused 2 units of blood. \\
\hline $\begin{array}{l}\text { Severe puncture site bleeding } \\
\text { (requiring transfusion) }\end{array}$ & 1 & Pressure dressing and stenting \\
\hline Reno-cutaneous fistula & 1 & Treated with analgesics \\
\hline Severe pain & 1 & \\
\hline URS & & Treated with analgesics \\
\hline Severe pain & 4 & Conservative \\
\hline Mild heamaturia & 4 & \\
\hline
\end{tabular}

\section{DISCUSSION}

Minimally invasive procedures for urolithiasis is common in our institution constituting about $11.7 \%$ of all surgical procedures done. From our study men are twice more likely to develop urinary stones than women. This is similar to a nationwide epidemiologic study by Sang Rake Bae et al in 2014 amongst Koreans where the male: female was 1.8:1. ${ }^{9}$ Most patients presenting with urolithiasis present with pain and this may be as a result of the movement of the stone or as a result of the hydronephrosis with stretching of the renal capsule.

It is apparent that urolithiasis can occur at any age and can be a diagnostic challenge in the first year of life. Children usually present with excessive crying and recurrent urinary tract infection and the diagnosis comes into mind when they have oliguria or anuria. Retrograde ureteroscopic laser lithotripsy is the procedure of choice for both ureteric stones and renal stones. Dauw Casey et al in 2015 found out that $80 \%$ of surgeons worldwide use ureteroscopy for renal stones less than $2 \mathrm{~mm}$, especially if the stone is in the lower calyx, with majority using high power laser . ${ }^{8,10}$

The other options are the use of the electrohydraulic with the ureteroscopic approach. Modalities like the pneumatic and ultrasonic can be used for ureteric stones and for stones in the renal pelvis. However, these modalities have the tendency to propel stone and a higher risk of perforating the ureter. Complications of intracorporeal lithotripsy depends on the approach and the modality of treatment. These may range from mucosal injuries, perforations, bleeding, guide wire breakage, and stones dropping into the retroperitonium. These may however depend on the experiences of the surgeon and the number of cases done per year. These may be less with increasing number of cases done. During one of our session of percutaneous nephtolithotomy (PCNL) a stone dropped into the retroperitoneium. This occurred during retrieval of stone without the amplatze sheath in place using forceps. It is likely that when the forceps got to lumbar fascia the prones of the forceps open dropping the stone.

Since fluoroscopy was the imaging modality being used it was easy to identify the stone and retrieve by forceps. Significant bleeding occurred in $2.3 \%$ of cases, mainly during PCNL sections, requiring blood transfusion. Jeane de la Rosette et al in a prospective study search found significant bleeding rate of $7.8 \%$ and a transfusion rate of $5.7 \%{ }^{11}$ Even though we had a lower rate possibly due a smaller sample size, it proves that these procedures are safe. 


\section{Special Article}

\section{CONCLUSION}

The commonest indications for intracorporeal lithotripsy at our centre was pain, followed by hydronephrosis. Commonest intraoperative complication was injury to the ureteral mucosa, whilst pain was the most common postoperative complication.

\section{REFERENCES}

1. Pearle MS, Nakada SY, editors. Epidemiology of stone disease: urolithiasis medical and surgical management. London: Informa Healthcare; 2009.1p

2. Chua ME, Gomez OR, Sapano LD, lim S, Marce limo L, Morales jnr ; Use of computed tomography scout film and Hounsfield unit of computed tomography in predicting the radio-opacity of urinary calculus in plain kidney ureter and bladder radiographs.uorAnn.com. jul-sep 2014, vol 6, (issue 3)

3. Karagülle O, Smorag U, Candir F, Gundermann G, Jonas U, Becker AJ, Gehrke A, Gutenbrunner C ; Clinical study on the effect of mineral waters containing bicarbonate on the risk of urinary stone formation in patients with multiple episodes of $\mathrm{CaOx}$-urolithiasis, World J Urol 2007 (25):315-323

4. Ohri N, Cooper B, Robertson W, Choong S, Rickards D, Unwin R; An Update and Practical Guide to Renal Stone Management. Nephron Clin Pract 2010; (116): c159-c171.

5. Jallouli M, Æ Mhiri R, Æ Nouri A ; Urolithiasis in infants, Pediatr Surg Int 2007 (23): 295-2997.
6. Ljunghall S, Danielson BG: A prospective study of renal stone recurrences. Br J Urol 1984; (56):122-124.

7. Jellison FC, Smith JC, Heldt JP, Spengler NM, Nicolay LI, Ruckle HC, et al. Effect of low dose radiation computerized tomography protocols on distal ureteral calculus detection. J Urol 2009; (182) :276.

8. Dauw Casey A., Simeon Laika S, Alruwaily Abdulrahman F., Sanguedolce F, Hollingsworth JM., Roberts William W., Faerber Gary J., Wolf J. Stuart Jr., and Ghani Khurshid R.. Contemporary Practice Patterns of Flexible Ureteroscopy for Treating Renal Stones: Results of a Worldwide Survey Journal of Endourology. November 2015, 29(11): 1221-1230. doi:10.1089/end.2015.0260

9. Sang Rak Bae, Jong-Mi S, Log Young Kim, Sung Hyun Paik, Hyeong Gon Kim, Yong Soo Lho, Hyoung Keun Park. The epidemiology of reno-ureteral stone disease in Koreans: a nationwide population-based study. Original Paper, Urolithiasis, April 2014, Volume 42, Issue 2, pp 109-114.

10. Schuster TG ; Hollenbeck BK ; Faerber GJ ; Stuart Wolf J Jr. Ureteroscopic treatment of lower pole calculi: Comparison of lithotripsy in situ and after displacement. Journal of Urology. 2002;168 (1):43-45.

11. Jean de la Rosette, Dean Assimos, Desai M, Gutierrez J, Lingeman J, Scarpa R, and Tefekli A . The Clinical Research Office of the Endourological Society Percutaneous Nephrolithotomy Global Study: Indications, Complications, and Outcomes in 5803 Patients. Journal of Endourology. January 2011, 25(1): 11-17. doi:10.1089/end.2010.0424. 